\title{
EKSPLORASI IDE-IDE MATEMATIKA PADA KESENIAN REYOG TULUNGAGUNG
}

\author{
Diesty Hayuhantika1, Dwi Shinta Rahayu ${ }^{2}$ \\ 1,2PendidikanMatematika, STKIP PGRI TULUNGAGUNG
}

diesti@stkippgritulungagung.ac.id ${ }^{1}$, d.shintarahayu@gmail.com²

\begin{abstract}
Abstrak
Pembelajaran matematika bersifat abstrak. Perlu sebuah inovasi pembelajaran dengan mempertimbangkan aspek kehidupan seharihari agar konsep-konsep matematika yang abstrak dapat dipahami oleh siswa. Matematika dan budaya merupakan dua hal yang saling berkaitan, jembatan antara keduanya disebut etnomatematika. Tujuan dari penelitian ini yaitu mendeskripsikan ide-ide matematika yang terdapat pada kesenian reyog Tulungagung. Fokus penelitian pada 6 unsur utama kesenian reyog Tulungagung. Penelitian ini adalah penelitian kualitatif dengan pendekatan etnografi. Hasil penelitian berupa ide matematis yang ditemukan berdasarkan bentuk fisik dari unsur-unsur kesenian reyog Tulungagung, diantaranya: (1) ide matematis pada gong yaitu lingkaran, bangun ruang sisi lengkung, volume benda putar, dan simetri, (2) ide matematis pada selompret yaitu bangun ruang sisi lengkung, volume benda putar, dan simetri, (3) ide matematis pada kenong yaitu lingkaran, bangun ruang sisi lengkung, dan volume benda putar, (4) ide matematis pada iker yaitu garis, keliling lingkaran, dan simetri, (5) ide matematis pada dhodhog yaitu lingkaran, bangun ruang sisi lengkung, volume benda putar, segitiga, dan korespondensi satusatu, (6) ide matematis pada goseng yaitu pencacahan dan aritmatika (penjumlahan dan perkalian). Selain itu terdapat pula ide matematis dari cara memainkan instrumen musik yaitu pola berulang.
\end{abstract}

Kata kunci: budaya, etnomatematika, matematika, reyog Tulungagung

\begin{abstract}
Mathematical learning is abstract. A learning innovation is needed by considering aspects of daily life so abstract mathematical concepts can be understood by students. Mathematics and culture are two interrelated things, the bridge between the two is called ethnomatematics. The focus of the research is on the 6 main elements of Reyog Tulungagung. This research is a qualitative research with ethnographic approach. The results of research in the form of mathematical ideas which are found based on the physical form of Reyog Tulungagung art elements, including: (1) mathematical ideas in gong, namely circles, arcing curved spaces, volumes of rotating objects, and symmetry; (2) mathematical ideas on the selompret, namely construct curved side spaces, rotating objects volume, and symmetry; (3) mathematical ideas on kenong namely circles, build curved side spaces, and rotary object volumes;
\end{abstract}


(4) mathematical ideas on iker namely lines, circumference of circles, and symmetry; (5) mathematical ideas on dhodhog, that are circles, arcing curves, volume of rotating objects, triangles, and one-to-one correspondence; (6) mathematical ideas on goseng namely counting and arithmetic (addition and multiplication). In addition there is also a mathematical idea of how to play musical instruments, namely repetitive patterns.

Keywords: culture, ethnomatematics, mathematics, reyog Tulungagung

\section{PENDAHULUAN}

Perkembangan ilmu pengetahuan dan teknologi tidak terlepas dari matematika. Matematika telah memegang peranan dalam aktivitas seharihari manusia. Matematika dibutuhkan untuk memecahkan permasalahan sehari-hari, membentuk pola pikir matematis dan mempelajari berbagai pengetahuan. Siswa mengangggap matematika adalah pelajaran yang sulit dan tidak mudah dipahami sehingga mengurangi minat siswa terhadap pelajaran matematika. Hal ini disebabkan karena soal matematika yang dipelajari di sekolah jauh dari konteks nyata dalam kehidupan sehari-hari siswa. Keabstrakan dalam matematika perlu diatasi dengan pemberian soal yang dekat dengan kehidupan sehari-hari untuk membantu pemahaman siswa. Diperlukan inovasi pembelajaran dengan mempertimbangkan aspekaspek budaya yang ada di lingkungan sekitar.

Guru diharapkan menyusun pembelajaran inovatif dengan memanfaatkan budaya sebagai sumber pembelajaran untuk membantu siswa memahami konsep matematika. Akan tetapi, seringkali guru mengalami kesulitan dalam mengaitkan konsep matematika dengan aspek budaya yang sesuai. Guru terlalu fokus dengan matematika yang ada di buku pembelajaran.Kadang, ia kehabisan ide untuk menyusun materi pembelajaran realistik yang sesuai.Padahal sumber atau referensi ide untuk pembelajaran matematika dapat diperoleh dari budaya sekitar.

Matematika dan budaya merupakan dua hal yang berkaitan satu dengan yang lain. Matematika tumbuh dan berkembang dibentuk oleh budaya. Wahyuni (2016) menyatakan bahwa matematika merupakan produk budaya dengan hasil abstraksi pikiran manusia, serta alat pemecahan masalah. Setiap budaya menciptakan ide-ide matematika sesuai dengan bentuk budaya yang ada di lingkungan tersebut, sehingga setiap budaya memiliki ide matematika yang berbeda. Eksplorasi ide matematika dan budaya ini disebut dengan etnomatematika.

Küçük (2014) menyatakan bahwa etnomatematika merupakan istilah yang digunakan untuk menjelaskan hubungan antara budaya dan matematika. Barton (1996) mengungkapkan etnomatematika adalah kajian 
yang meneliti cara sekelompok budaya tertentu dalam memahami, mengekspresikan, dan menggunakan konsep-konsep serta praktik kebudayaan yang digambarkan sebagai sesuatu yang matematis. Secara tidak sadar masyarakat telah menggunakan konsep dan ide matematika dalam aktivitas kehidupan. Mulai dari aktivitas jual beli di pasar, mengukur, berhitung, permainan, seni budaya, arsitektur, dan lain-lain. Etnomatematika menggunakan konsep matematika secara luas, dengan tujuan agar siswa memahami, mengolah, dan menggunakan ide-ide matematika yang dipelajari sehingga dapat memecahkan masalah yang berkaitan dengan aktivitas sehari-hari.

Pembelajaran berbasis etnomatematika membuat lingkungan belajar menjadi menyenangkan. Siswa dapat terlibat aktif di kelas karena belajar berdasarkan budaya yang sudah mereka kenal sehingga hasil belajar dan tujuan pembelajaran dapat tercapai dengan lebih baik. Pembelajaran matematika berbasis etnomatematika terbukti efektif dalam meningkatkan kemampuan pemahaman matematika siswa (Sarwoedi, Marinka, Febriani, Wirne, 2018). Selain itu, etnomatematika membantu mengembangkan pemahaman siswa tentang budaya sehingga siswa tidak merasa asing dengan budaya khas daerahnya masing-masing.

Penelitian terdahulu terkait etnomatematika sudah banyak dilakukan. Diantaranya penelitian Ekowati, Kusumaningtyas, \& Sulistyani (2017) tentang pembelajaran dengan media batik madura, tari khas trenggal dan tari khas madura; penelitian Febriyanti, Prasetya, \& Irawan (2018) pada permainan tradisional engklek dan gasing khas budaya sunda; dan penelitian Charitas \& Prahmana (2018) mengenai eksplorasi kegiatan merancang desain kebaya kartini. Dari penelitian relevan tersebut, belum ada penelitian terkait eksplorasi ide-ide matematika pada kesenian reyog Tulungagung.

Indonesia dikenal memiliki berbagai macam budaya yang tersebar di seluruh daerah. Budaya universal dibagi menjadi tujuh unsur, yaitu bahasa, sistem pengetahuan, organisasi sosial, sistem peralatan hidup dan teknologi, sistem mata pencaharian hidup, sistem religi, dan kesenian (Rachmawati, 2012). Kebiasaan-kebiasaan yang dilakukan dalam masyarakat dapat membentuk suatu budaya. Dengan demikian, setiap daerah terdapat budaya asli yang menjadi ciri khas masyarakat.

Sebagai salah satu daerah yang berada di jawa timur, Tulungagung memiliki berbagai macam budaya khas. Salah satu pertunjukan tari tradisional yang merupakan seni budaya daerah di Tulungagung, yaitu kesenian reyog kendang. Kesenian ini sebelumnya bernama "Reyog Kendhang", kemudian pada tahun 2010 resmi mengganti nama menjadi "Reyog Tulungagung" dan mendapat pengakuan dari HKI Kementrian Hukum dan HAM Republik Indonesia (Irfan, 2017). Kesenian reyog sudah tidak asing 
lagi bagi masyarakat, namun masyarakat kita lebih familier dengan reyog Ponorogo. Reyog Tulungagung berbeda dengan reyog Ponorogo, keduanya memiliki karateristik dan keunikan masing-masing. Kesenian reyog Tulungagung dimainkan oleh 6 orang atau kelipatannya dengan masingmasing penari menari sambil memainkan kendang dodhog yang dibawanya. Terdapat 12 gerakan pokok dan setiap gerakan tersebut memiliki filosofi tersendiri (Damayanti, Agung, \& Cahyadi, 2018). Menurut Shanti (2017) terdapat 6 unsur utama yang berkaitan dengan sejarah terbentuknya kesenian reyog Tulungagung yaitu gong, selompret, kenong, iker, dhodhog, dan gongseng. Keenam unsur reyog Tulungagung tersebut memiliki potensi dalam kajian etnomatematika, yaitu berkaitan dengan konsep matematika.

Tujuan dari penelitian ini adalah mendeskripsikan ide-ide matematika yang terdapat pada kesenian reyog Tulungagung, khususnya pada 6 unsur utama dari kesenian reyog Tulungagung. Penelitian ini penting untuk dikaji, mengingat pendekatan budaya pada pembelajaran matematika akan membantu siswa dalam mempelajari materi matematika yang bersifat abstrak. Selain itu, kesenian reyog Tulungagung erat kaitannya dengan kehidupan siswa sehari-hari. Maka dari itu, guru memerlukan sumber referensi ide untuk membuat bahan pembelajaran berbasis etnomatematika.

\section{METODE PENELITIAN}

Penelitian ini merupakan penelitian kualitatif menggunakan pendekatan etnografi, yang bertujuan untuk memperoleh deskripsi dan analisis mendalam tentang konsep-konsep matematika dalam budaya melalui penelitian lapangan. Penelitian ini dilakukan mulai bulan April 2019.

Hal yang dilakukan pertama kali dalam fase pertama adalah menetapkan objek etnomatematika yaitu kesenian Reyog Tulungagung. Berikutnya mengkaji literatur untuk merumuskan fokus penelitian, serta menetapkan aspek-aspek potensial dari kesenian Reyog Tulungagung.Dalam kajian ini hanya difokuskan pada 6 unsur kesenian Reyog Tulungagung yang berkaitan dengan aspek sejarahnya. Selanjutnya menetapkan informan yang terdiri dari 2 orang sejarawan, 2 orang budayawan dari Dinas Kebudayaan Pariwisata Pemuda dan Olahraga Kabupaten Tulungagung, 2 orang pelatih Reyog Tulungagung yang berasal dari Sanggar Dhodhog Sadjiwo Djati dan Acarya Nirwasita, serta 6 penari dari kelompok tari Acarya Nirwasita. Pemilihan sanggar Dhodog Sadjiwo Djati dan Acarya Nirwasita kerena sanggar tersebut sudah berdiri cukup lama. Ia merupakan sanggar kesenian besar, memiliki eksistensi tinggi di tengah pesatnya kesenian modern, dan masih menerapkan gerakan reyog yang pakem. Kegiatan selanjutnya adalah penyusunan instrumen pendukung berupa pedoman wawancara dan 
pedoman observasi. Instrumen yang disusun dikomunikasikan dengan rekan Dosen Program Studi Pendidikan Matematika dari STKIP PGRI Tulungagung.

Fase kedua dilakukan pengambilan data. Fase ini diawali dengan melakukan kunjungan awal ke tempat masing-masing informan untuk menentukan secara detail waktu dan tempat pelaksanaan wawancara dan observasi. Pada waktu yang telah ditentukan, peneliti melakukan wawancara yang bertujuan untuk menggali informasi tentang unsur-unsur kesenian Reyog Tulungagung serta sejarahnya. Peneliti juga melakukan observasi secara langsung terhadap unsur-unsur Kesenian Reyog Tulungagung tersebut serta mengambil dokumentasi untuk kelengkapan data di Sanggar Dhodhog Sadjiwo Djati dan kelompok tari Acarya Nirwasita. Di samping itu, peneliti juga melakukan penggalian arsip untuk memperoleh informasi tentang sejarah Reyog Tulungagung di Dinas Kebudayaan Pariwisata Pemuda dan Olahraga Kabupaten Tulungagung.

Setelah data terkumpul dilanjutkan ke fase 3, yakni menganalisis data. Semua data yang terkumpul dikategorikan berdasarkan aspek-aspek potensial. Selanjutnya konsep-konsep matematika formal yang tersirat di dalam kesenian Reyog Tulungagung dianalisis dan direduksi. Data yang telah tereduksi kemudian dikonsultasikan kepada 2 ahli matematika dari Universitas Negeri Malang serta dibandingkan dengan konsep matematika formal yang terdapat pada literatur yang relevan. Hal ini bertujuan untuk mendapatkan data yang valid dan reliabel. Data disajikan dalam tabel dan narasi. Selanjutnya, dilakukan penarikan kesimpulan tentang ide-ide matematika (formal) yang terdapat pada kesenian Reyog Tulungagung. Kesimpulan ini merupakan hasil etnomatematika kesenian Reyog Tulungagung pada enam unsurnya yang berkaitan dengan aspek sejarah.

\section{HASIL DAN PEMBAHASAN}

Kesenian Reyog Tulungagung merupakan kesenian tradisional ciri khas daerah Tulungagung yang berupa tarian oleh 6 orang yang masingmasing membawa alat musik dhodhog serta diiringi oleh alunan musik dari beberapa instrumen lainnya. Kesenian ini memiliki banyak nilai, salah satunya adalah nilai simbolis yang terkandung pada sejarahnya dan tercermin pada unsur-unsur penyusunnya. Kajian ini memfokuskan pada penggalian ide-ide matematika yang terdapat pada 6 unsur utama Reyog Tulungagung.

Ada berbagai versi sejarah kesenian Reyog Tulungagung. Berdasarkan hasil penelusuran pustaka serta wawancara terhadap beberapa narasumber, sejarah kesenian Reyog Tulungagung cenderung mengacu pada kisah Dewi Kilisuci, putri Kerajaan Kediri yang dilamar oleh Raja Bugis. Raja Bugis mengutus para prajurit untuk melamar Dewi Kilisuci. Dalam perjalanan dari 
Bugis menuju Kediri, para prajutrit tersebut menemui hambatan di Madiun, hingga salah arah melewati jalur Ponorogo, Trenggalek, Tulungagung, hingga akhirnya sampai di Kediri. Setelah sampai di Keraton Kediri, prajurit tersebut menyampaikan amanat Sang Raja untuk melamar Sang Putri. Akan tetapi, Sang Putri menolak secara halus dengan mengajukan enam persyaratan. Para prajurit hendak menyampaikan persyaratan tersebut kepada Sang Raja. Dalam perjalannya kembali, sebelum menghadap Raja para prajurit meminta bantuan masyarakat Tulungagung untuk mengartikan persyaratan tersebut. Adapun keenam persyaratan tersebut adalah sebagai berikut.

1. "Mata ayam tukung sebesar terbang miring yang digantung di gubug penceng". Hal ini diartikan sebagai alat musik gong yang digantung di gayornya yang menjadi salah satu instrumen pengiring dalam Reyog Tulungagung.

2. "Seruling pohon padi sebesar batang kelapa". Hal ini dimaknai dengan alat musik selompret, sebagai pengiring musik Reyog Tulungagung.

3. "Dendeng Tuma sak tetelan pulut". Hal ini diwujudkan dengan alat musik kenong, sebagai instrumen pengiring Reyog Tulungagung.

4. "Ati tengu sebesar guling". Hal ini diartikan dengan iker yang dijadikan sebagai ikat kepala oleh penari Reyog Tulungagung.

5. "Madu lanceng enam bumbung". Hal ini diwujudkan dengan "dhodhog" atau kendang yang ditabuh oleh masing-masing penari Reyog Tulungagung, sebanyak 6 buah, yaitu kendang 1 (arang), kendang 2 (kerep), imbal 1, imbal 2, keplak, dan trinthing.

6. "Binggel emas yang bisa berbunyi sendiri". Hal ini dimaknai dengan gongseng yaitu perlengkapan yang dipakai di kaki penari Reyog Tulungagung.

Keenam persyaratan yang diajukan oleh Dewi Kilisuci tersebut diwujudkan dalam instrumen yang menjadi unsur utama dari Kesenian Reyog Tulungagung. Adapun ide-ide matematis yang terdapat pada keenam unsur tersebut disajikan pada Tabel 1 berikut.

Tabel 1 Ide-ide Matematis pada Unsur-unsur Kesenian Reyog Tulungagung

\begin{tabular}{lll}
\hline No & \multicolumn{1}{c}{$\begin{array}{c}\text { Unsur-Unsur Kesenian Reyog } \\
\text { Tulungagung }\end{array}$} & \multicolumn{1}{c}{ Ide-ide Matematis } \\
\hline $1 . \quad$ Gong & ・ Lingkaran \\
& & - Bangun ruang sisi lengkung \\
& & - Volume benda putar \\
& &
\end{tabular}


Lanjutan Tabel 1 Ide-ide Matematis pada Unsur-unsur Kesenian Reyog Tulungagung

\begin{tabular}{|c|c|c|}
\hline No & $\begin{array}{c}\text { Unsur-Unsur Kesenian Reyog } \\
\text { Tulungagung } \\
\end{array}$ & Ide-ide Matematis \\
\hline 2. & Selompret & - Bangun Ruang Sisi lengkung \\
\hline 3. & Kenong & $\begin{array}{l}\text { - Lingkaran } \\
\text { - Bangun ruang sisi lengkung } \\
\text { - Volume benda putar }\end{array}$ \\
\hline
\end{tabular}

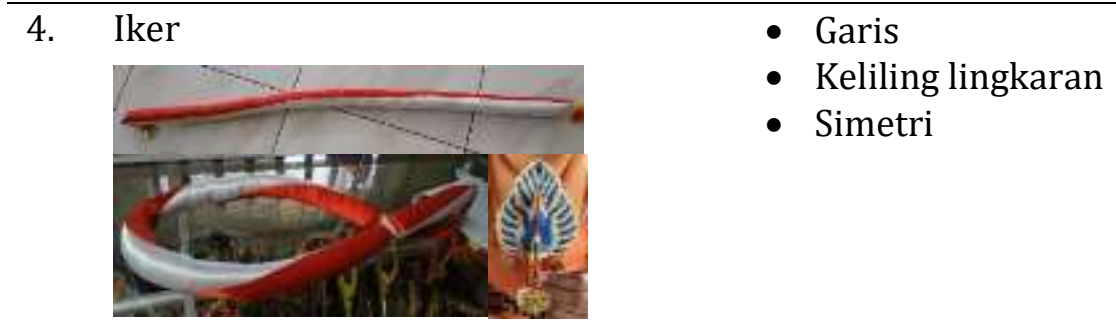

\section{Dhodhog}

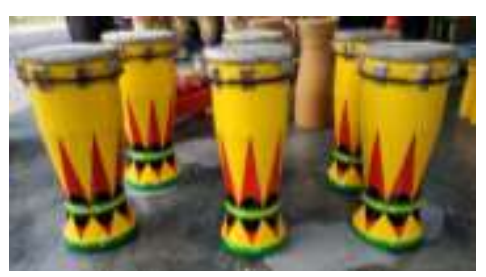

- Lingkaran

- Bangun ruang sisi lengkung

- Volume benda putar

- Segitiga

- Korespondensi satu-satu: antara dhodhog dengan masing-masing penari

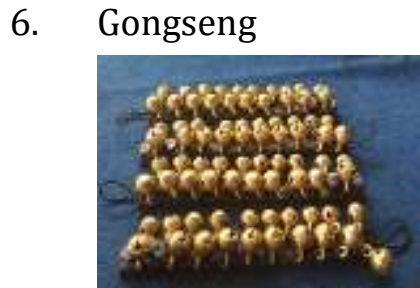

- Bangun ruang sisi lengkung

- Pencacahan

- Aritmetika: penjumlahan, perkalian

Ide-ide matematis yang disajikan pada Tabel 1 tersebut merupakan ide matematis berdasarkan bentuk fisik dari masing-masing unsur kesenian Reyog Tulungagung. Di samping itu, terdapat pula ide matematis dari cara memainkan instrumen tersebut dan iramanya yaitu pola berulang (repeating pattern). Beberapa pola ritme dalam kesenian Reyog Tulungagung disajikan pada Tabel 2. 
Tabel 2. Pola Ritme Iringan Musik Reyog Tulungagung Pola Ritme 1

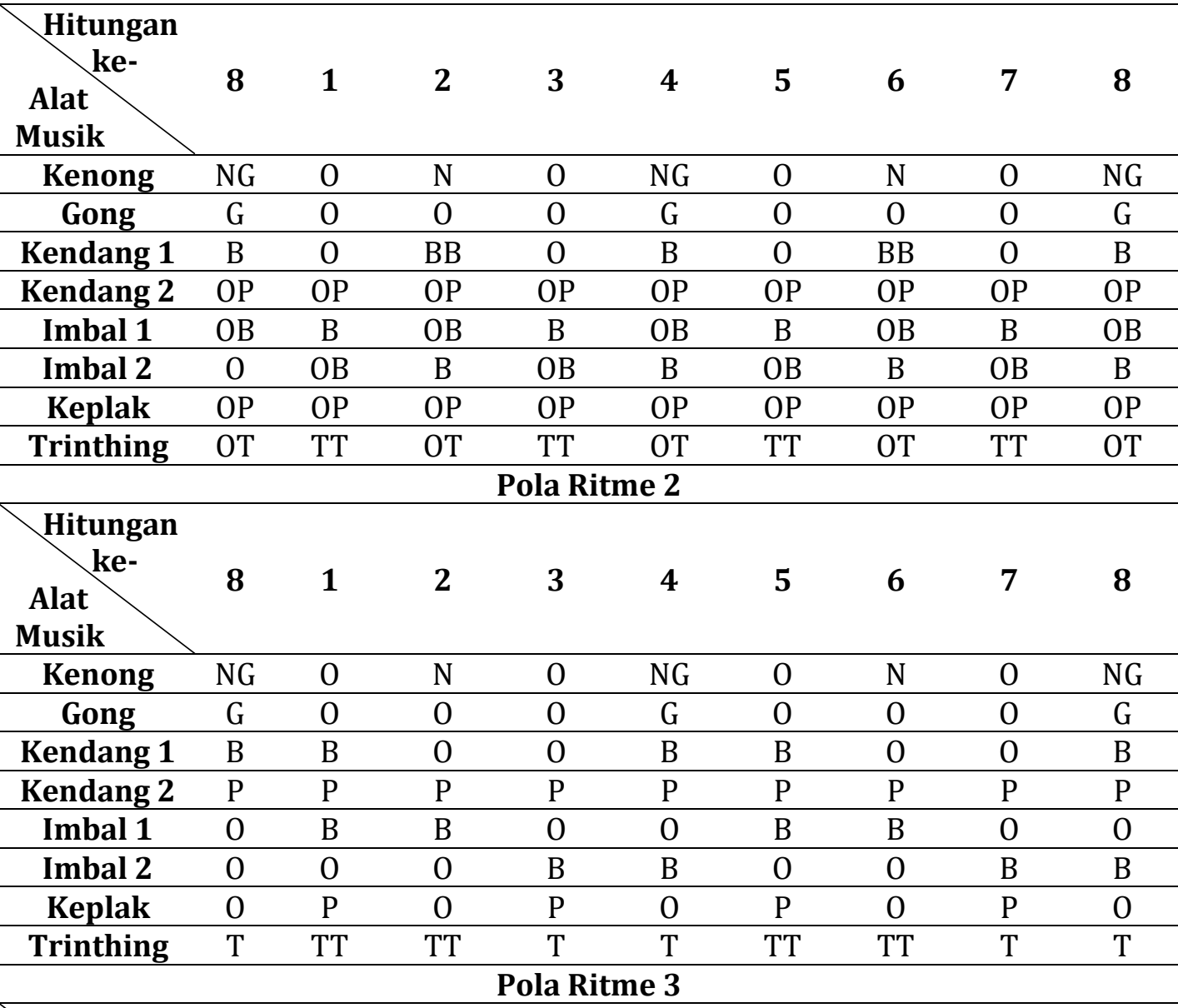

Hitungan

$\begin{array}{lllllllllll}\text { Alat } & 8 & 1 & 2 & 3 & 4 & 5 & 6 & 7 & 8\end{array}$

Musik

\begin{tabular}{cccccccccc}
\hline Kenong & $\mathrm{NG}$ & $\mathrm{O}$ & $\mathrm{N}$ & $\mathrm{O}$ & $\mathrm{NG}$ & $\mathrm{O}$ & $\mathrm{N}$ & $\mathrm{O}$ & $\mathrm{NG}$ \\
\hline Gong & $\mathrm{G}$ & $\mathrm{O}$ & $\mathrm{O}$ & $\mathrm{O}$ & $\mathrm{G}$ & $\mathrm{O}$ & $\mathrm{O}$ & $\mathrm{O}$ & $\mathrm{G}$ \\
\hline Kendang 1 & $\mathrm{O}$ & $\mathrm{B}$ & $\mathrm{O}$ & $\mathrm{B}$ & $\mathrm{B}$ & $\mathrm{B}$ & $\mathrm{O}$ & $\mathrm{B}$ & $\mathrm{B}$ \\
\hline Kendang 2 & $\mathrm{P}$ & $\mathrm{P}$ & $\mathrm{P}$ & $\mathrm{P}$ & $\mathrm{P}$ & $\mathrm{P}$ & $\mathrm{P}$ & $\mathrm{P}$ & $\mathrm{P}$ \\
\hline Imbal 1 & $\mathrm{O}$ & $\mathrm{BB}$ & $\mathrm{O}$ & $\mathrm{BB}$ & $\mathrm{O}$ & $\mathrm{BB}$ & $\mathrm{O}$ & $\mathrm{BB}$ & $\mathrm{O}$ \\
\hline Imbal 2 & $\mathrm{O}$ & $\mathrm{O}$ & $\mathrm{BB}$ & $\mathrm{O}$ & $\mathrm{BB}$ & $\mathrm{O}$ & $\mathrm{BB}$ & $\mathrm{O}$ & $\mathrm{BB}$ \\
\hline Keplak & $\mathrm{O}$ & $\mathrm{PO}$ & $\mathrm{PO}$ & $\mathrm{PO}$ & $\mathrm{PO}$ & $\mathrm{PO}$ & $\mathrm{PO}$ & $\mathrm{PO}$ & $\mathrm{PO}$ \\
\hline Trinthing & $\mathrm{O}$ & $\mathrm{TT}$ & $\mathrm{TO}$ & $\mathrm{TT}$ & $\mathrm{TO}$ & $\mathrm{TT}$ & $\mathrm{TO}$ & $\mathrm{TT}$ & $\mathrm{TO}$ \\
\hline
\end{tabular}

\section{Eksplorasi Ide-Ide Matematis pada Kesenian Reyog Tulungagung}

\section{Ide matematis berdasarkan bentuk fisik}

Hasil eksplorasi ide-ide matematis yang terkandung dalam 6 unsur utama kesenian reyog Tulungagung, sebagai berikut : 


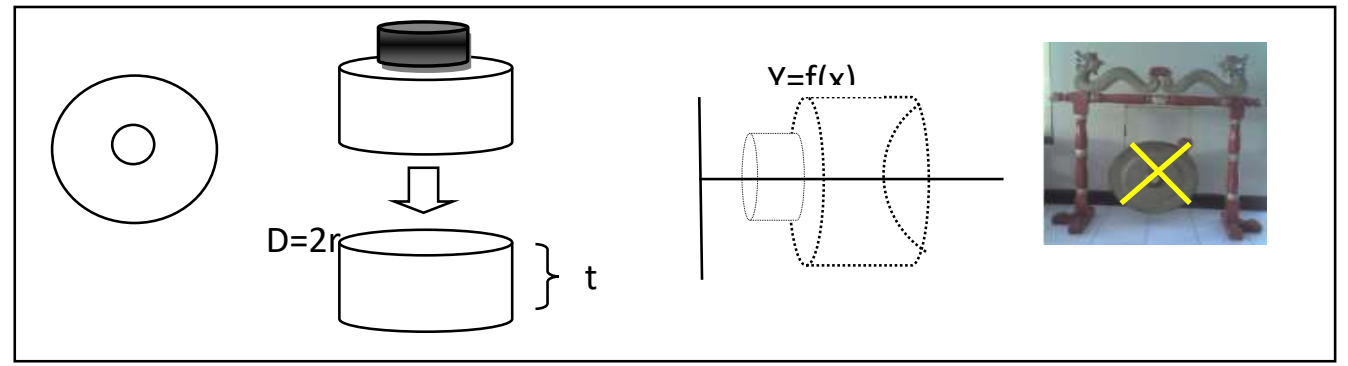

Gambar 1 Ide Matematis pada Gong

Unsur yang pertama yaitu gong. Bentuk gong terdiri dari 2 bangun ruang. Banyak konsep matematika terkandung dalam alat kesenian gong ini. Dari gambar di atas, terlihat ide pembelajaran matematis yang bisa dipakai guru, yaitu (1) pada lingkaran: mengidentifikasi bangun datar lingkaran, mengukur diameter dan jari-jari lingkaran, menghitung luas lingkaran, (2) pada bangun ruang sisi lengkung: megidentifikasi bangun ruang sisi lengkung, menghitung luas permukaan tabung, luas selimut, tinggi, diameter, jari-jari, alas tabung dengan tutup atau tanpa tutup dan volume tabung, (3) volume benda putar, (4) simetri: simetri lipat dan simetri putar.

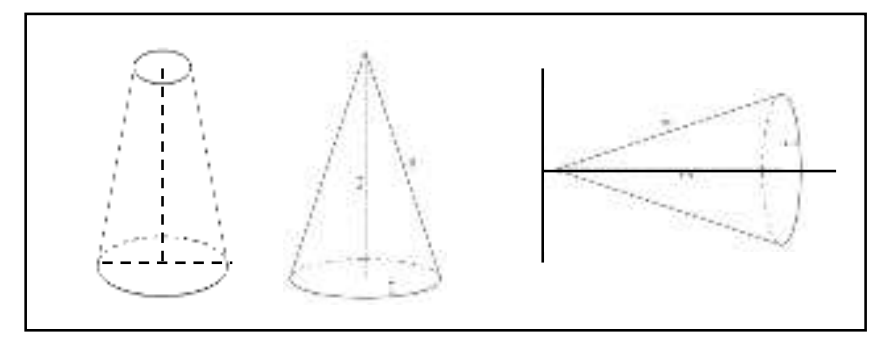

Gambar 2 Ide Matematis pada Selompret

Unsur yang kedua yaitu selompret. Selompret berbentuk seperti bangun ruang kerucut (kerucut dan kerucut terpancung). Banyak konsep matematika dalam alat kesenian selompret ini. Dari gambar di atas tampak bahwa ide matematis pada pembelajaran yang bisa dipakai guru yaitu (1) bangun ruang sisi lengkung: mengidentifikasi bangun ruang sisi lengkung, mencari diameter, jari-jari, tinggi, selimut, dan luas permukaan kerucut, (2) menghitung volume benda putar, (3) simetri.

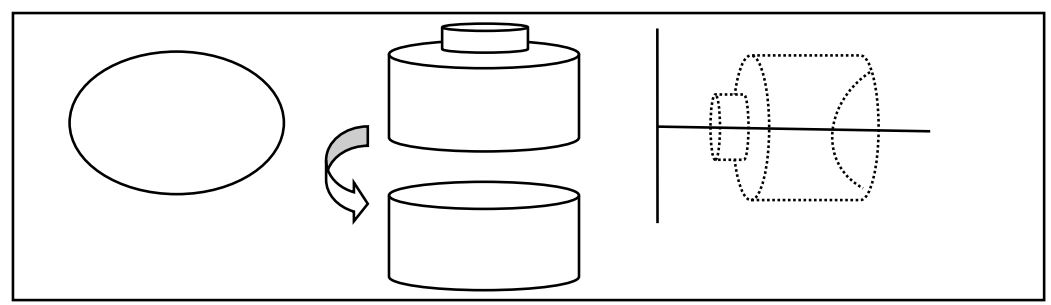

Gambar 3 Ide Matematis pada Kenong 
Unsur yang ketiga yaitu kenong. Bentuk kenong terdiri dari 2 bangun ruang tabung. Pada gambar di atas ditunjukkan bahwa konsep matematika yang terdapat pada kenong yaitu bangun datar lingkaran, bangun ruang sisi lengkung, dan volume benda putar. Ide matematis pada pembelajaran yang bisa dipakai guru, yaitu (1) lingkaran: mengidentifikasi bangun datar lingkaran, mengukur diameter dan jari-jari lingkaran, menghitung luas lingkaran, (2) bangun ruang sisi lengkung: megidentifikasi bangun ruang sisi lengkung, menghitung luas permukaan tabung, luas selimut, tinggi, diameter, jari-jari, alas tabung dengan tutup atau tanpa tutup dan volume tabung, (3) menghitung volume benda putar.

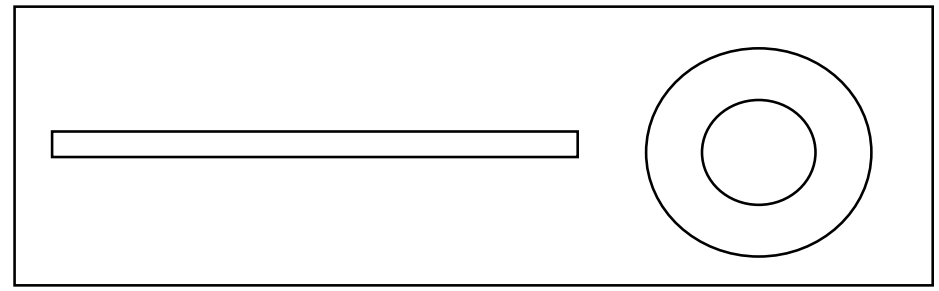

Gambar 4 Ide Matematis pada Iker

Unsur yang keempat yaitu iker. Bentuk iker seperti suatu garis yang dibentuk menjadi lingkaran. Dari gambar di atas menunjukkan bahwa ide matematis pada pembelajaran yang bisa dipakai guru yaitu garis, keliling lingkaran, simetri.

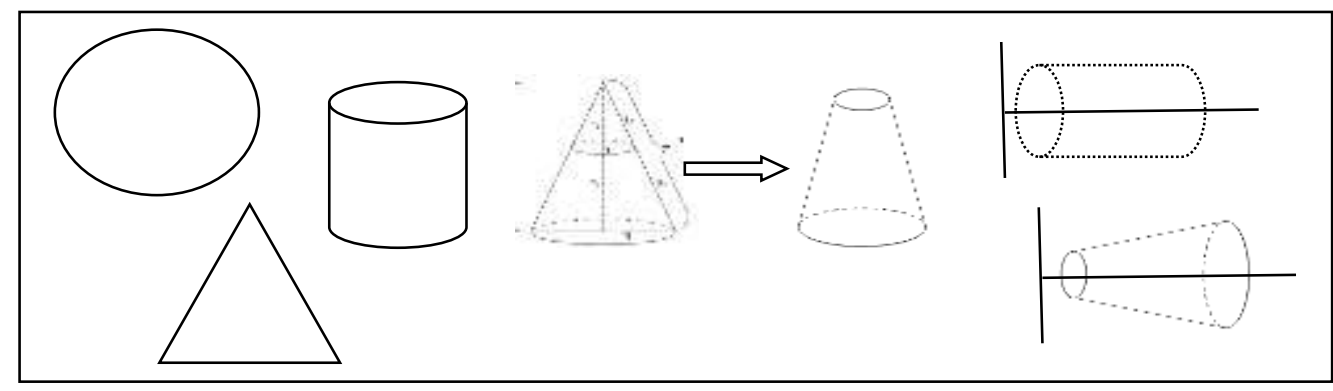

Gambar 5 Ide Matematis pada Dhodhog

Unsur yang kelima yaitu dhodhog. Jika diamati, dhodhog berbentuk seperti tabung atau kerucut. Pada gambar di atas menunjukkan bahwa konsep matematika yang terdapat pada dhodhog yaitu bangun datar lingkaran, bangun ruang sisi lengkung, volume benda putar, segitiga, dan korespondensi satu-satu (antara dhodhog dengan masing-masing penari). Ide matematis pada pembelajaran yang bisa dipakai guru yaitu (1) bangun datar lingkaran: mencari jari-jari, diameter, apotema, busur, tembereng, tali busur, juring, luas, dan keliling lingkaran, (2) bangun datar segitiga: mengidentifikasi sifat-sifat segitiga, menghitung luas, dan keliling segitiga (3) bangun ruang sisi lengkung tabung dan kerucut: mengidentifikasi bangun 
ruang sisi lengkung, mencari diameter, jari-jari, tinggi, selimut, dan luas permukaan bangun ruang, (4) menghitung volume benda putar, (5) korespondensi satu-satu: antara dhodhog dengan masing-masing penari, merupakan materi relasi dan fungsi, misalnya ada 2 himpunan A dan B berkorespondensi satu-satu apabila setiap anggota A berpasangan tepat dengan satu anggota himpunan $\mathrm{B}$.

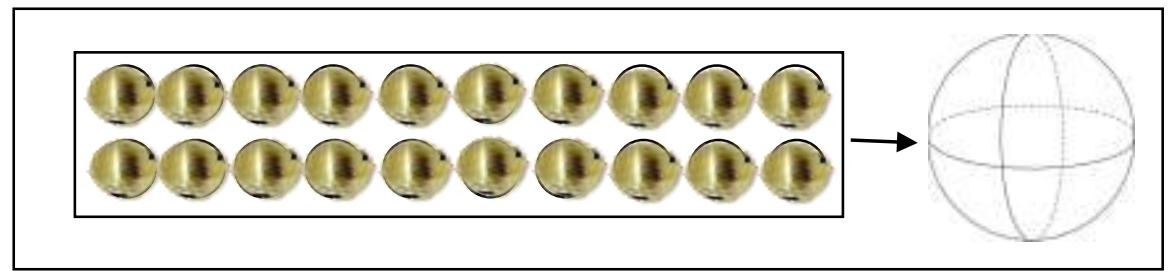

Gambar 6 Ide Matematis pada Gongseng

Unsur yang keenam yaitu gongseng. Gongseng dipakai pada kaki dengan bentuk berupa lonceng-lonceng kecil yang digantung melingkar pada sepotong kulit lembu dan diikat dengan tali. Lonceng kecil pada gongseng ini berbentuk seperti bangun ruang bola. Ide matematis pada pembelajaran yang bisa dipakai guru yaitu (1) bangun ruang sisi lengkung: mengidentifikasi unsur-unsur bola, luas permukaan bola, dan volume bola. (2) pencacahan, (3) aritmatika: penjumlahan dan perkalian. Pada materi penjumlahan, misalnya menghitung banyaknya lonceng pada gongseng A dan gongseng B. Untuk materi perkalian, misalnya mengalikan 4 gongseng dimana setiap gongseng terdapat 15 lonceng.

\section{Ide matematis dari cara memainkan instrumen}

Instrumen musik merupakan unsur penting dalam pertunjukan reyog Tulungagung. Sebagai instrumen pengiring reyog, biasanya dilantunkan gending-gending atau lagu-lagu secara instrumental. Bazinet \& Marshall (2015) menyatakan bahwa terdapat hubungan yang erat antara musik dan matematika. Instrumen musik reyog Tulungagung jika dimainkan menghasilkan pola ritme atau irama, ketika diamati dapat membentuk pola matematika. Ide matematis dari cara memainkan instrumen tersebut yaitu pola berulang (repeating pattern).

Berdasarkan Tabel 2 di atas, berikut merupakan pola berulang pada setiap ritme instrumen musik reyog Tulungagung:

1. Pola ritme 1 :

NG G B OP OB O OP OT - O O O OP B OB OP TT - N O BB OP OB B OP OT O $O 0$ OP B OB OP TT - NG G B OP OB B OP OT - O O O OP B OB OP TT N O BB OP OB B OP OT - O O O OP B OB OP TT - NG G B OP OB B OP OT Pola tersebut bisa ditulis $\mathrm{ABCBABCBA}$

2. Pola ritme 2: 
NG G B P O O O T - O O B P B O P TT - N O O P B O O TT - O O O P O B P TNG G B P O B O T - O O B P B O P TT - N O O P B O O TT - O O O P O B P TNG G B P O B O T

Pola tersebut bisa ditulis ABCBABCBA

3. Pola ritme 3 :

NG G OP O 000 - O O B P BB O PO TT - N O O P O BB PO TO O O B P BB O PO TT - NG G B P O BB PO TO - O O B P BB O PO TT N O O P O BB PO TO - O O B P BB O PO TT - NG G B P O BB PO TO

Pola tersebut dapat ditulis ABCBABCBA

Selain pola berulang pada semua instrumen musik setiap hitungan, terdapat pula pola berulang pada masing-masing instrumen musik. Berikut pola bilangan pada ritme 1 :

1. Kenong : NG-O-N-O-NG-O-N-O-NG, dapat ditulis ABCBABCBA

2. Gong : G-O-O-O-G-O-O-O-G, dapat ditulis ABBBABBBA

3. Kendang 1 : B-O-BB-O-B-O-BB-O-B, , dapat ditulis ABCBABCBA

4. Kendang 2 : OP-OP-OP-OP-OP-OP-OP-OP-OP, , dapat ditulis AAAAAAAAA

5. Imbal 1 : OB-B-OB-B-OB-B-OB-B-OB, , dapat ditulis ABABABABA

6. Imbal 2 :O-OB-B-OB-B-OB-B-OB-B, , dapat ditulis ABCBCBCBC

7. Keplak :OP-OP-OP-OP-OP-OP-OP-OP-OP, , dapat ditulis AAAAAAAAA

8. Trinting : OT-TT-OT-TT-OT-TT-OT-TT-OT, , dapat ditulis ABABABABA

Untuk mempelajari pola berulang, yang harus diperhatikan yaitu komponen penyusun pola berulang tersebut. Pola ritme 1, 2, dan 3 memiliki pola berulang yaitu ABCBA, sedangkan untuk (1) kenong pada ritme 1, 2, dan 3 memiliki pola ABCBA, (2) gong pada ritme 1,2,3 memiliki pola ABBBA, (3) kendang 1: pada ritme 1 memiliki pola $A B A B A$, pada ritme 2 dengan pola AABBAA, pada ritme 3 dengan pola $\mathrm{ABABBBAB}$, (4) kendang 2 pada ritme 1, 2, dan 3 memiliki pola AAAAA, (5) imbal 1: pada ritme 1 memiliki pola ABABA, pada ritme 2 dengan pola ABBAA, pada ritme 3 dengan pola ABABA, (6) imbal 2: pada ritme 1 memiliki pola $A B C B A$, pada ritme 2 dengan pola AABBAA, ritme 3 dengan pola ABABA, (7) keplak: pada ritme 1 dengan pola AAAAA, pada ritme 2 dengan pola ABABA, pada ritme 3 dengan pola AAAAA, (8) trinting: pada ritme 1 dengan pola $A B C B A$, pada ritme 2 dengan pola ABBAA, dan pada ritme 3 dengan pola ABABA.

Pola berulang merupakan kegiatan bernalar dalam matematika. Permasalahan yang berkaitan dengan pola berulang di atas, misal menggunakan ritme dari gong yaitu G-O-O-O-G-O-O-O-G atau ABBBABBBA. Dari pola ABBBABBBA, diketahui bahwa jumlah huruf A yaitu 3 dan jumlah huruf $B$ yaitu 6, dengan pola pertama yaitu ABBB. Contoh permasalahan lain, misalnya mencari jumlah huruf A dan Huruf B untuk 100 pengulangan pola tersebut. 


\section{KESIMPULAN DAN SARAN}

Berdasarkan hasil dan pembahasan di atas, maka dapat disimpulkan bahwa 6 unsur utama kesenian reyog Tulungagung terdapat ide matematis yang dapat digunakan sebagai referensi guru untuk menyusun pembelajaran berbasis budaya. Etnomatematika sebagai jembatan antara matematika dengan budaya memberikan pengalaman pembelajaran yang lebih bermakna. Hal ini karena etnomatematika merupakan pembelajaran berbasis budaya sehingga siswa lebih mengenal budaya khas daerahnya.

Hasil eksplorasi menunjukkan pada kesenian reyog Tulungagung ditemukan etnomatematika terkait ide-ide matematis yaitu pada bentuk fisik kesenian reyog Tulungagung yang dapat digunakan untuk mempelajari konsep bangun datar lingkaran, segitiga, bangun ruang sisi lengkung tabung, kerucut, bola, volume benda putar, garis, simetri, korespondensi satu-satu, pencacahan dan aritmatika. Sedangkan pada pola ritme musik reyog Tulungagung digunakan untuk mempelajari pola berulang.

Berdasarkan hasil penelitian ini, disarankan peneliti lain untuk meneliti lebih luas lagi terkait etnomatematika pada kesenian Reyog Tulungagung. Selain itu, disarankan untuk guru agar menyusun pembelajaran menggunakan etnomatematika dan menjadikan hasil penelitian ini sebagai sumber ide penyusunan pembelajaran.

\section{UCAPAN TERIMA KASIH}

Ucapan terima kasih kepada pihak DRPM Ristekdikti yang telah menyediakan dana hibah penelitian ini dalam skim Penelitian Dosen Pemula.

\section{DAFTAR PUSTAKA}

Barton, W. D. (1996). Ethnomathematics: Exploring Cultural Diversity in Mathematics. University of Auckland, Auckland.

Bazinet, R., \& Marshall, A. M. (2015). Ethnomusicology, Ethnomathematics, and Integrating Curriculum. General Music Today, 28(3), 5-11.

Charitas, R., \& Prahmana, I. (2018). Ethnomathematics: exploring the activities of designing kebaya kartini. MaPan: Jurnal Matematika Dan Pembelajaran, 6(1), 10-19.

Damayanti, P. R., Agung, A., \& Cahyadi, J. (2018). Perancangan Media Pendukung Tentang Sejarah Reyog Kendang Tradisi Khas Tulungagung Dalam Video Animasi. Jurnal DKV Adiwarna, 1(12), 1-10.

Ekowati, D. W., Kusumaningtyas, D. I., \& Sulistyani, N. (2017). Ethnomathematica Dalam Pembelajaran Matematika (Pembelajaran 
Bilangan Dengan Media Batik Madura, Tari Khas Trenggal Dan Tari Khas Madura). Jurnal Pemikiran Dan Pengembangan SD, 5(2), 716-721.

Febriyanti, C., Prasetya, R., \& Irawan, A. (2018). Etnomatematika Pada Permainan Tradisional Engklek dan Gasing Khas Kebudayaan Sunda. Barekeng: Jurnal Ilmu Matematika Dan Terapan, 12(1), 1-6.

Irfan, M. N. (2017). Perkembangan Kesenian Reyog Tulungagung. AVATARA, 5(3), 1112-1122.

Küçük, A. (2014). Ethnomathematics in Anatolia-Turkey: Mathematical Thoughts in Multiculturalism. Revista Latinoamericana de Etnomatemática, 7(1), 171-184.

Rachmawati, I. (2012). Eksplorasi Etnomatematika Masyarakat Sidoarjo. MATHEdunesa, 1(1), 1-8.

Sarwoedi, Marinka, D. O., Febriani, P., \& Wirne, I. N. (2018). Efektifitas Etnomatematika dalam Meningkatkan Kemampuan Pemahaman Matematika Siswa Pendahuluan. Jurnal Pendidikan Matematika Raflesia, 03(02), 171-176.

Shanti, U. A. (2017). Kesenian Reog Kendang Tulungagung sebagai Inspirasi Pengembangan Motif Batik di Kabupaten Tulungagung. Prosiding. Seminar Nasional Seni dan Desain: "Membangun Tradisi Inovasi Melalui Riset Berbasis Praktik Seni dan Desain" FBS Unesa : 196-202.

Wahyuni, I. (2016). Eksplorasi Etnomatematika Masyarakat Pesisir Selatan Kecamatan Puger Kabupaten Jember. Fenomena, 15(2), 225-238. 